\title{
GEOLOGY AND EXPLORATION OF THE KELSEY LAKE DIAMONDIFEROUS KIMBERLITES, COLORADO, U.S.A.
}

Coopersmith, Howard G.

Ashton Mining Limited, P.O. Box 1916, Fort Collins, Colorado 80522 U.S.A.

\section{Introduction}

A cluster of several kimberlites comprise the Relsey Lake Project, a Joint Venture between Diamond Company NL (a Member Company of the Ashton Mining Groupl and Moonstone Diamond Corporation (a private Company). These are currently being evaluated for their commercial diamond potential.

The cluster is in the northern state Line Rimberlite District of the Colorado/Wyoming Diamond Province. The cluster comprises the Schaffer, Maxwell, and Aultman kimberlite pipes. Two relatively large pipes and a few smaller bodies, termed the Relsey lake kimberlites, are being investigated. Various other properties in the District have been evaluated for. diamond, with results ranging from zero diamonds to close to 1 carat per hundred tonne. No deposits have yet been recognized as economically viable. A location map is presented as Figure 1.

The Relsey Lake kimberlites are depicted on Figure 2. These were in part previously referred to as the Schaffer 8 group (McCallum and co-workers). This project concentrated on the evaluation of the two largest pipes, KL-1 and RL-2. These were mapped, and sampled for kimberlite minerals and microdiamonds. Mineral chemistry was favorable for diamond occurrence. Microdiamonds and small diamonds were recovered from weathered surface samples. The bodies were drilled for delineation and mapping.

\section{Geology}

The Relsey Lake kimberlites form a small group of irregular shaped pipes and fissures (Figure 2). The pipes intrude Proterozoic granitic rocks of the Sherman and Log Cabin Batholiths. Shape is largely controlled by jointing in the country rock. The kimberlite intrudes $1400 \mathrm{my}$ granite, contains sedimentary xenoliths of Cambrian to Early Devonian age, and is presently overlain by Pennsylvanian-Permian sedimentary formations. Isotopic ages of other kimberlites in the district are in the $390 \mathrm{my}$, or Early Devonian, range, which fit well with geological ages seen at Relsey Lake.

The KL-1 pipe was shown to be a multiphase pipe of diatreme facies and crater facies kimberlite, with a surface area of approximately 12 acres. Pellet-rich tuffisitic serpentine kimberlite breccia occupies the southern fissure appendage of the main pipe. This was extremely rich in mantle xenocrysts, megacrysts and xenoliths. The south-central portion of the pipe contains pellet-and autolith-rich layered pyroclastic kimberlite, generally of a sandy tuff. This is significant as crater facies kimberlite had not previously been observed in state line District kimberlites. Quantity of quartz sand and sedimentary xenolith material varied between and within layers. Very large (to $3 \mathrm{~m}$ ) 
sedimentary xenolith blocks were locally present. This zone had a moderate amount of mantle xenocrystal and xenolithic material. The main pipe, comprising the northern blow, was not sampled (or drilled) due to difficult access. The very northern edge of the main pipe contains tuffisitic serpentine kimberlite breccia with a moderate amount of mantle component.

The KL-2 pipe is a multiphase diatreme facies complex, with a surface area in excess of 8 acres. No crater facies material was noted. At least four distinct phases of tuffisitic serpentine kimberlite breccia are present. These are locally rich in mantle xenocrysts and xenoliths.

Sedimentary xenolith content, size and preservation varies considerably between phases. Alteration and carbonatization is also variable. The northern part of the pipe contains abundant crustal xenoliths in excess of $1 \mathrm{~m}$. Occurrence of contact breccia is indicated.

Late stage alteration and surface weathering has destroyed much of the primary mineralogy of both bodies of kimberlite. Ubiquitous phenocrystal and macrocrystal olivine is totally replaced by serpophitic or lizardite serpentine, and often later carbonatized. Groundmass diopside, perovskite, apatite and opaques are generally preserved. Groundmass serpentine and calcite may be either primary or secondary. Macrocrysts and xenocrysts of Mg-ilmenite, pyrope, spinels, phlogopite and Cr-diopside are generally preserved, as are megacrysts of Mg-ilmenite, Cr-poor titanian pyrope and sub-calcic diopside. Groundmass in autoliths and pellets is relatively fresh, and generally phlogopite-rich.

Petrographically these rocks are Group 1 kimberlites.

Xenolithic material in the pipes includes upper mantle garnet peridotite, spinel peridotite, eclogite, lower crustal granulite, and crustal granitic, metamorphic and sedimentary rocks. Content and size ranges of xenolithic and megacrystal material varies widely within the pipes.

\section{Bulk Sample Testing}

Approximately 1000 tonnes of in situ kimberlite was bulk sampled for diamond processing, roughly 500 tonnes each from the RL-1 and RL-2 pipes. Sample sites were chosen to be representative of the pipe. Sample was excavated only from definite in situ kimberlite rock below the zone of most intense surface weathering.

Sample was trucked to a contract Diamond Test Plant. The plant generally consisted of crushing, scrubbing, screening, recrushing, Heavy Media Separation, Sortex $x$-ray sorting and grease table circuits. Basically all $2 \mathrm{~mm}$ to $25 \mathrm{~mm}$ material was tested for diamond. Recovery efficiency was continually monitored. Near 100 per cent recovery was obtained.

\section{Diamonds}

The diamonds are generally colorless. Some stones have a faint to strong brownish-pink color. The industrial stones are only partly translucent, due primarily to their multicrystalline aspect. In general, the larger stones are of better color. Diamond sizes ranged from under 0.05 carat to greater than 1 carat. 
Diamond morphology is dominated by primary octahedral forms. Multicrystalline aggregates are common. Some macles are present, along with other minor forms. Resorption has modified most octahedra to tetrahexahedral forms, ranging from pristine octahedra to various rounded stages. Surface etching is weak to moderate. Deformation features are common, dominated by lamination lines. Broken stones are common. Differential resorption and preserved primary surface features suggest a prolonged xenolithic transport and protection.

\section{Results and Conclusions}

The Relsey Lake kimberlites were shown to be complex pipes of diatreme facies and locally crater facies material. This is the first known occurrence of crater facies kimberlite in the province. Several phases of kimberlite are present; all represent classical Group 1 kimberlites. The pipes are typical of other state Line District occurrences, with the mantle components and diamonds being more similar to other pipes in the northern part of the District.

A first pass bulk sample diamond test was completed on the Relsey Lake 1 and 2 kimberlite pipes. Encouraging diamonds were recovered but overall grades were low. Size, color and clarity of the diamonds are considered good. Alluvial diamond potential of the property has not yet been assessed.

\section{Acknowledgements}

Ashton Mining Limited and Moonstone Diamond Corporation are thanked for permission to perform and present this work. M.E. McCallum, G.P. Gregory and R. Baxter-Brown provided useful discussions in the field. R. Falk painstakingly described the diamonds. M.B. Burrell ably managed the field and plant operations.
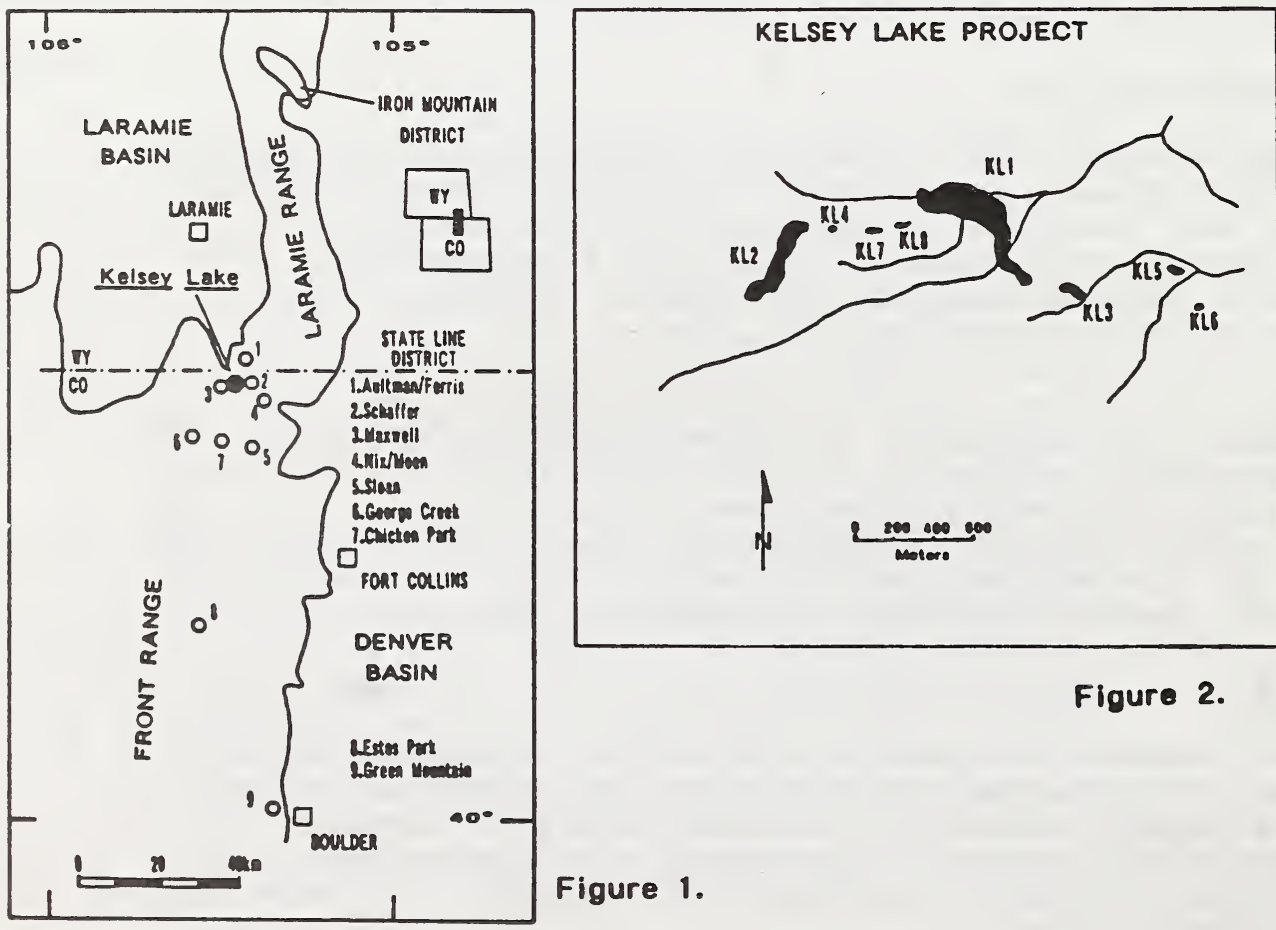

Figure 2. 